\title{
First Trimester Screening for Trisomy 21 by Maternal Age, Nuchal Translucency and Fetal Nasal Bone in Unselected Pregnancies
}

\author{
Ksenija Gersak ${ }^{1}$, Maja Pohar-Perme ${ }^{2}$ and Darija M. Strah ${ }^{3}$ \\ ${ }_{1}^{1}$ Department of Obstetrics and Gynecology, University Medical Center Ljubljana \\ 2Institute for Biostatistics and Medical Informatics, Faculty of Medicine, \\ University of Ljubljana \\ ${ }^{3}$ Diagnostic Centre Strah, Domzale \\ Slovenia
}

\section{Introduction}

Screening programs play a significant role in the assessment of fetal chromosomal defects and provide the appropriate prenatal counseling and diagnostic tests.

Every pregnant woman has a risk that her fetus might be affected by trisomy 21 . At the beginning of the 1980's the screening based on a woman's age was introduced. With the cutoff age of 35 years, $5 \%$ of the pregnant women population were classified as "high-risk". However, only $30 \%$ of fetuses with trisomy 21 were detected in this group while the majority of trisomy 21 babies were born to mothers from the "low-risk" group.

Later, biochemical screening tests in the second trimester became widely used. The test is based on the concentration of various fetoplacental markers in the maternal circulation: alpha-fetoprotein (AFP), unconjugated estriol (uE3), human chorionic gonadotropin (hCG) and inhibin-A. This method of screening is proved to be more effective than maternal age alone and at the same rate of invasive testing (about 5\%) it can identify about 50 to $70 \%$ of the fetuses with trisomy 21 (Nicolaides KH 2004).

In the 1990's screening tests were moved to the first trimester. The woman's age was first combined with sonographic measurement of fetal nuchal translucency and fetal heart rate. Later sonographic screening was upgraded by the measurement of maternal serum free $\beta$ human chorionic gonadotropin $(\beta-\mathrm{hCG})$ and pregnancy-associated plasma protein-A (PAPP-A) (Wright D et al, 2008; Kagan KO et al, 2008). Fetal nuchal translucency screening identifies 75 to $80 \%$ of fetuses with trisomy 21 at a false positive rate of $5 \%$.

In the last 10 years, several additional first trimester sonographic markers have been described (nasal bone, tricuspid flow, ductus venosus flow) which improve the detection rate of chromosomal abnormalities and reduce the false positive rate. At a risk cut-off of 1 in 100 , the detection rate of trisomy 21 is about $95 \%$ at a false positive rate of $2.5 \%$.

The ability to achieve reliable measurements and evaluation of sonographic markers depends on an appropriate training of sonographers, adherence to a standard ultrasound technique in order to achieve uniformity of results among different operators (Nicolaides $\mathrm{KH}$ 2011). Health professionals undertaking the first trimester scan have to be adequately 
trained and their results have to be subjected to an audit. The Fetal Medicine Foundation (FMF) has introduced a process of training and certification to help establish high standards of scanning on an international basis (www.fetalmedicine.com).

\subsection{Nuchal translucency}

Nuchal translucency (NT) is the assessment of the amount of fluid behind the neck of the fetus, also known as the nuchal fold. An anechoic space is visible and measurable sonographically in all fetuses between the $11^{\text {th }}$ and $14^{\text {th }}$ weeks of pregnancy (Figure 1 ). Underlying pathophysiological mechanisms for nuchal fluid collection include cardiac dysfunction, venous congestion in the head and neck, altered composition of the extracellular matrix, failure of lymphatic drainage, fetal anemia or hypoproteinemia and congenital infection (Nicolaides KH 2004). Accumulation of nuchal fluid decreases after the $14^{\text {th }}$ week. Enlarged NT helps us to identify the high-risk fetuses for trisomy 21 and other chromosomal abnormalities (Nicolaides KH et al, 1992; Nicolaides KH et al, 1994).

NT is evaluated in fetuses with crown-rump length (CRL) range from 45 to $84 \mathrm{~mm}$. The scan may be performed transabdominally but in some cases transvaginal approach may be beneficial. During the measurement, the fetus lies in a neutral position, with the head in line with the spine (www.fetalmedicine.com). The assessment of the NT is obtained in a midsagittal view of the fetal profile. The measurements are taken with the inner border of the horizontal line and callipers are placed on the line that defines the NT thickness. Normally, NT increases with the CRL.

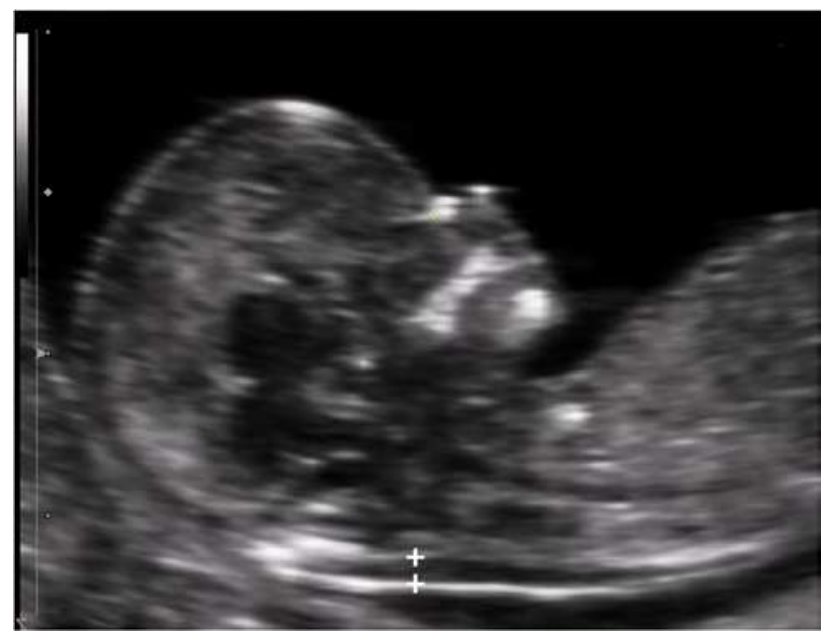

Fig. 1. Measurement of nuchal translucency behind the neck of the fetus.

\subsection{Nasal bone}

The nasal root depth is abnormally short in 50\% of trisomy 21 cases (Cicero S et al, 2003). Sonographic studies at the $15^{\text {th }}$ to $22^{\text {nd }}$ weeks of gestation reported that about $65 \%$ of trisomy 21 fetuses had an absent or abnormally short nasal bone. The fetal nasal bone can be visualized between the $11^{\text {th }}$ and $14^{\text {th }}$ weeks of gestation, when CRL is between 45 and 84 $\mathrm{mm}$. The assessment of the nasal bone should be obtained in a mid-sagittal view of the fetal 
profile (Figure 2). The image of the nose includes three lines. The top line represents the nasal skin, in continuity with the skin is the tip of the nose, and the bottom line represents the nasal bone which is thicker and more echogenic.

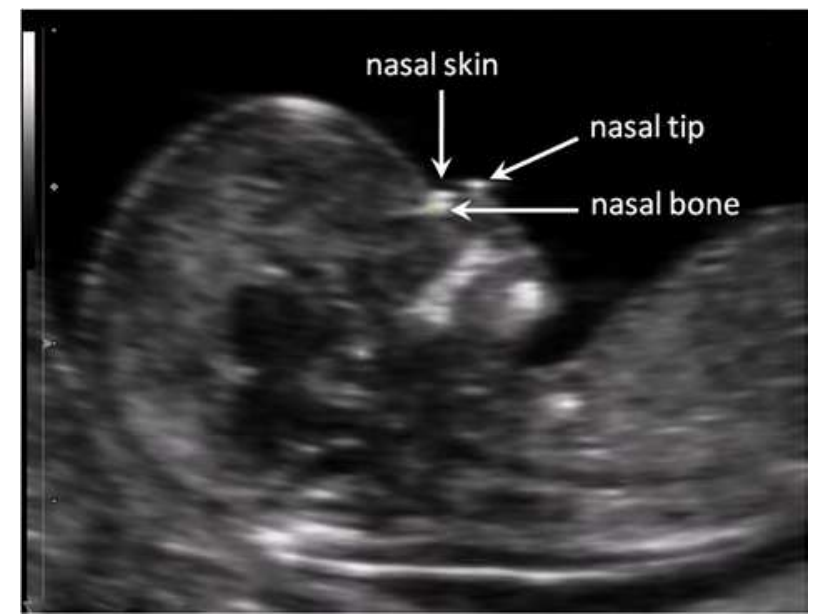

Fig. 2. Assessment of the nasal bone in a mid-sagittal view of the fetal profile.

\section{Sonographic screening for trisomy 21 by maternal age, nuchal translucency and fetal nasal bone}

The best performance of first trimester screening is achieved by a combination of maternal age, serum biochemical testing and multiple sonographic markers. But Doppler assessment of tricuspid and ductus venosus flow can be time consuming and it requires properly trained sonographers. As a first stage policy the assessment only by maternal age, nuchal translucency and fetal nasal bone, without biochemical testing, has some advantages (Nicolaides KH 2011). Beside the examination of fetal anatomy which leads to early diagnosis of many abnormalities in all pregnancies, the major advantage is the reduction in the cost of screening. The measurement of biochemical markers is undertaken only in the subgroup with positive first stage screening results.

Our study reports the results of the first trimester trisomy 21 risk assessment by a combination of maternal age, sonographic measurement of fetal NT thickness and assessment of fetal nasal bone in unselected pregnancies in Slovenia.

\section{Subjects and methods}

The study included all pregnant women appointed for the first trimester ultrasound screening examination at a single outpatient clinic between January 4, 2005 and April 30, 2010. Before the screening they all received counseling by their level one gynaecologists and an information leaflet about the ultrasound examination and the aim of screening.

At the time of the visit, they gave details about their demographic characteristics and medical history, which were entered into the computer database. The examinations were carried out by two experienced sonographers, certified by the Fetal Medicine Foundation Certificate of Competence in the $11^{\text {th }}$ to $14^{\text {th }}$ weeks scan. 
In the majority of the cases the examination was performed transabdominally within 20 minutes. In less than $1 \%$ of the cases a transvaginal ultrasound examination had to be carried out.

In the fetal CRL less than $45 \mathrm{~mm}$, the pregnant woman was given a new appointment, while in the fetal CRL more than $83 \mathrm{~mm}$, only a detailed ultrasound scan was performed and the pregnant woman received further information about the possibility of the second trimester biochemical test.

For the examinations we used 2-5 $\mathrm{MHz}$ and 3.7-9.3 $\mathrm{MHz}$ transducers GE Healthcare Voluson 730 Pro, Milwaukee, USA, and 4-6 MHz, 4-7 MHz, 5-9 MHz and 7-9 $\mathrm{MHz}$ transducers Acuson S2000, Siemens Medical Solutions, Mountain View CA, USA.

Only singleton pregnancies with live fetus from the $11^{\text {th }}$ to $14^{\text {th }}$ weeks of gestation with the CRL of 45-83 mm were included in the further analysis. Pregnancy outcomes were obtained from the participating women, referred by level one gynecologists and paediatricians. Karyotype results were reported by the three cytogenetic laboratories.

\subsection{Statistical methods}

Risks were calculated according to the FMF program, following the FMF guidelines (Snijders RJM et al, 1999; www.fetalmedicine.com). The distribution of maternal age of the examined women was compared to the age distribution in the pregnant population in Slovenia for the time interval 2005-2010 (www.stat.si).

We calculated the sensitivity, false positive rate, positive predictive value and negative predictive value for a cut-off risk of 1 in 300. We accompanied the most important results with a 95\% confidence interval. The balance between the false positive rate and the detection rate was studied and the trends were inspected graphically. The cut-off risk that would yield 5\% false positives was calculated for trisomy 21 .

Additionally, the expected numbers for the Slovene population were estimated by weighting the values of each woman according to the frequency of her age in the Slovene population.

\section{Results}

\subsection{Study population}

A total of 13,535 pregnant women were offered first trimester screening for detecting fetal chromosomal abnormalities at a single outpatient clinic between January 4, 2005 and April 30, 2010.

The sample represented unselected population of pregnant women of Caucasian ethnic origin. Twin pregnancies (3.6\% of the cases, 486 of 13,535) were excluded. All further analyses included 13,049 women with singleton pregnancies.

\subsection{Age distribution}

The average maternal age (at the time of screening) was 29 years (range 11 to $47, \mathrm{SD}=3.9$ ) with a distribution as shown in the Figure 3 (black columns). When compared to the age distribution in the pregnant population in 2005-2010 in Slovenia, the average maternal age was the same - 28.9 years (Figure 3, red columns). The pregnant population however varied more, in particular there was a larger proportion of women aged 36 and more in the Slovene pregnant population $(10.2 \%)$ as compared to only $3.6 \%$ in our sample. The sample on the other hand included a considerably larger percent of the women between 26 and $30(47.9 \%$ 
compared to $40.6 \%$ ). Only $2.5 \%$ were 37 and older compared to the $7.2 \%$ in the population of Slovene pregnant women.

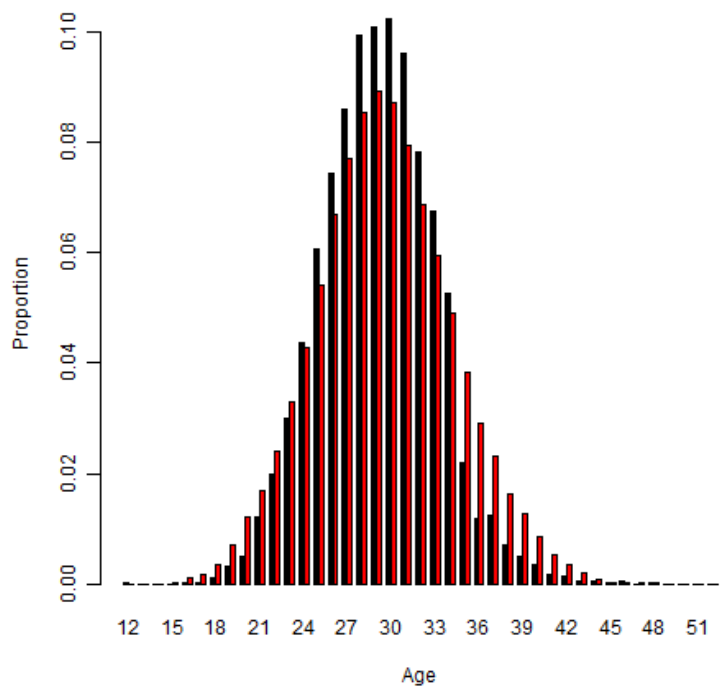

Fig. 3. Age distribution comparison at screening; Slovene population (red columns), our sample of unselected population of pregnant women (black columns).

\subsection{The screening results}

The average gestation was 12 weeks 4 days (range 11 weeks 1 day to 14 weeks 0 days). The average fetal CRL was $63.2 \mathrm{~mm}$ (range 45 to $83 \mathrm{~mm}$ ). And the average NT thickness was 1.7 $\mathrm{mm}$ (range 0.9 to $13.4 \mathrm{~mm}$ ).

The distribution of NT for fetal CRL in normal pregnancies and pregnancies with fetuses affected by chromosomal abnormalities is shown in Figure 4. The NT was above the 95th centile of the normal range for the CRL in 75\% (15 of 20) of trisomy 21 pregnancies and in $64 \%$ (16 of 25) pregnancies with other chromosomal abnormalities.

At the time of testing in 3\% of all pregnancies $(394$ of 13,049) the estimated risk for trisomy 21 was 1 in 300 or higher, considering the calculation based on FMF program. Three hundred and sixty cases $(2.8 \%)$ turned out to be false positive. At the invasive testing, chromosomal abnormalities were identified in $8.6 \%$ of high risk cases (34 of 394), which represents one case of fetal chromosomal abnormality detected per 12 invasive diagnostic procedures.

\subsection{Detection rate}

We detected 34 out of 45 cases with chromosomal abnormalities (75.6\%), diagnosed prenatally or postnatally.

Trisomy 21 was detected in 20 cases (Figure 4). Among women with an estimated risk of 1 in 300 or higher there were 17 cases of trisomy 21 . The detection rate for trisomy 21 was $85 \%$ (17 out of 20 ), the $95 \%$ confidence interval for the detection rate was $[69.4,100]$. The positive predictive value for the trisomy 21 was $4.3 \%$ (17 of 394); and the negative predictive value was $99.98 \%(12,652$ of 12,655$)$. 


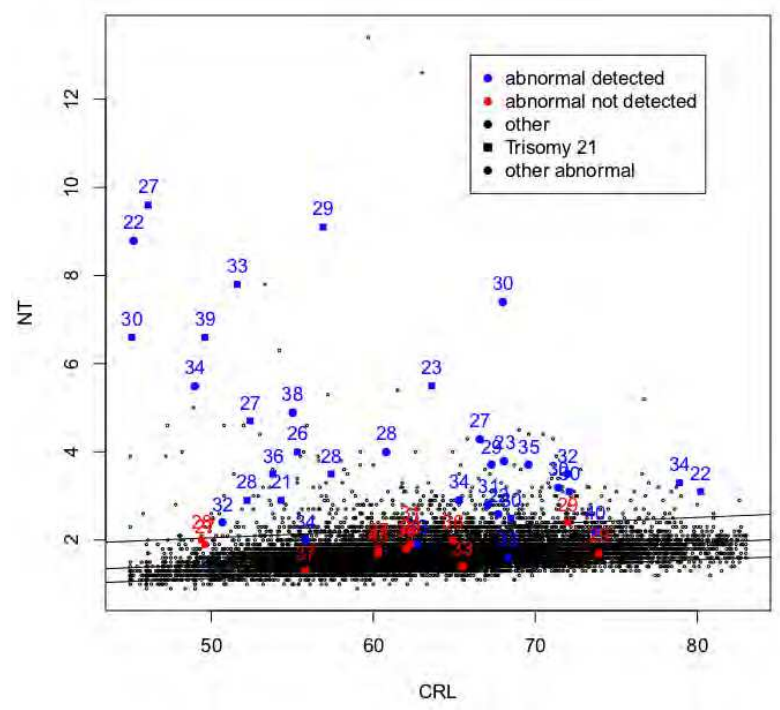

Fig. 4. Distribution of NT (in $\mathrm{mm}$ ) with respect to CRL (in $\mathrm{mm}$ ) in our sample. The curves present the 5th, 50th and 95th centiles.

Other chromosomal abnormalities were diagnosed in 25 cases (Figure 4). Among women with an estimated risk of 1 in 300 or higher there were 17 cases of other chromosomal abnormalities. The detection rate was $68 \%$ (17 out of 25$)$. The $95 \%$ confidence interval for the detection rate was $[49.7,86.3]$. The positive predictive value for the other chromosomal abnormalities was $4.3 \%$ (17 of 394); and the negative predictive value was $99.94 \%(12,647$ of $12,655)$.

The diagnosed chromosomal abnormalities and their frequencies are presented in Table 1. The assessment of nasal bone was performed in $98.5 \%$ of the cases $(12,847$ out of 13,049$)$. In 12 cases nasal bone was absent $(0.1 \%)$, and in 3 out of those 12 cases $(25 \%)$, the chromosomal abnormality was detected.

\begin{tabular}{|l|l|}
\hline Karyotype & No. \\
\hline Trisomy 21 & 20 \\
\hline Trisomy 18 & 10 \\
\hline Trisomy 13 & 2 \\
\hline $45, X$ (Turner syndrome) & 3 \\
\hline $47, X X Y$ & 2 \\
\hline Mosaic structure & 3 \\
\hline Unbalanced structural rearrangements & 5 \\
\hline Total & $\mathbf{4 5}$ \\
\hline
\end{tabular}

Table 1. Chromosomal abnormalities in fetuses and newborns in our sample of 13,049 women with singleton pregnancies. 


\subsection{The risk threshold}

The risk values of the undetected cases of trisomy 21 were as follows: 1 in 1979, 6365, 7435; for other chromosomal abnormalities they were 1 in 493, 872, 1102, 1279, 2016, 2180, 3816, 6731.

It was thus clear that a less conservative limit for probability threshold (for example 1 in 500 ) would not yield different detection rate in case of trisomy 21, but would rather improve the detection of other chromosomal abnormalities.

These changes are explored in Figure 5, which shows how detection rate would change by changing the risk threshold. The black curve shows how detection rate of trisomy 21 changes by changing the risk threshold (value 200 implies probability threshold set at 1/200). The red curve represents the same information for other chromosomal abnormalities. The numbers above the points indicate the percentage of false positives that would occur in our sample at that threshold.

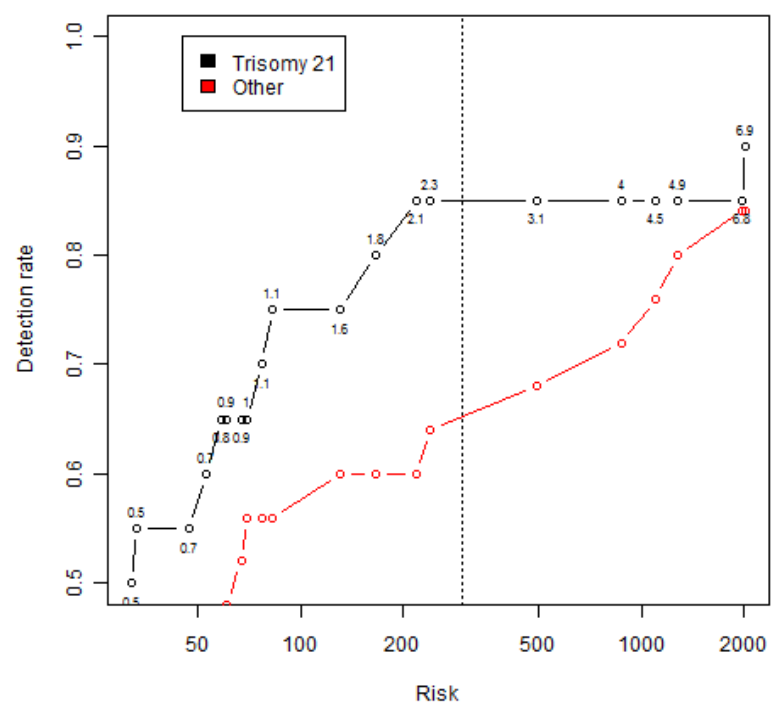

Fig. 5. Detection rate of trisomy 21 (black curve) and other chromosomal abnormalities (red curve) with respect to the risk threshold set (value 200 implies probability threshold set at $1 / 200)$. The numbers above the points give the false positive rate.

Inversely, Figure 6 shows the detection rate with respect to the percentage of false positives, the numbers above the points indicate the risk threshold (value 200 implies threshold $1 / 200)$.

\subsection{Prediction for the Slovene population}

Since the age distribution in our sample was different from the age distribution in the Slovene pregnant women population, we can expect all the above results to be slightly different. In particular, the rate of false positives can be expected to change. Figure 7 gives the false positive rate in our sample with respect to calendar year and compares it to the predicted false positive rate in the Slovene pregnant women population. 
Inversely, Figure 8 gives the probability threshold that would result in the $5 \%$ false positives rate.

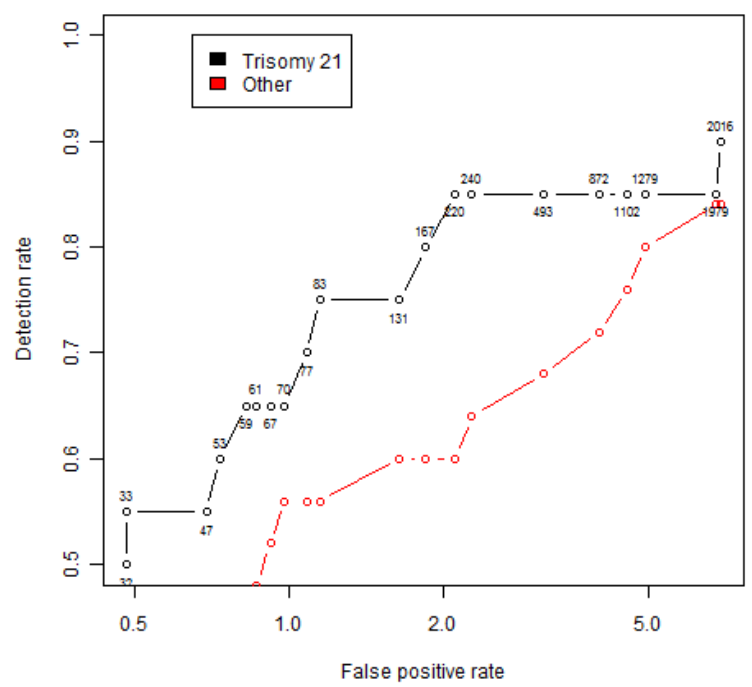

Fig. 6. Detection rate of trisomy 21 (black curve) and other chromosomal abnormalities (red curve) with respect to the false positive rate. The numbers above the points give the risk threshold (value 200 implies probability threshold set at 1/200).

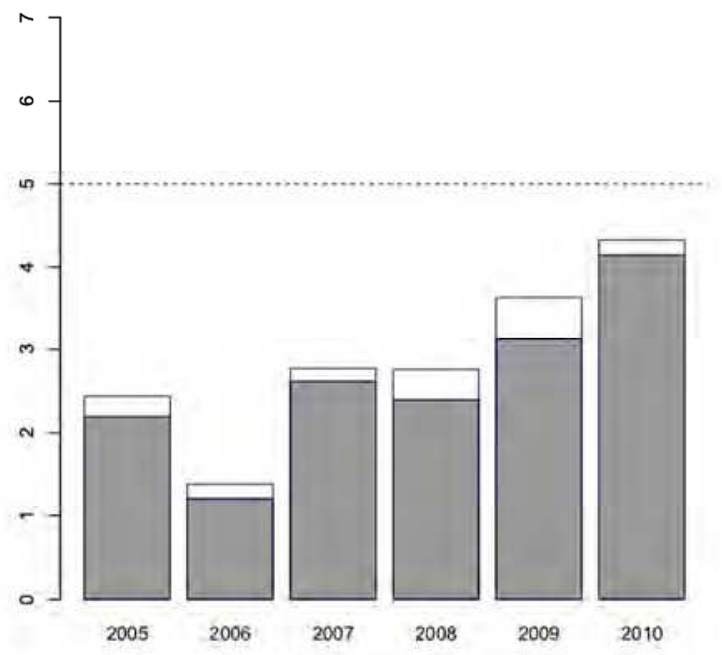

Fig. 7. The percentage of false positives in our sample (gray columns) and the predicted false positive rate in the Slovene pregnant women population (white columns) with respect to calendar year. 


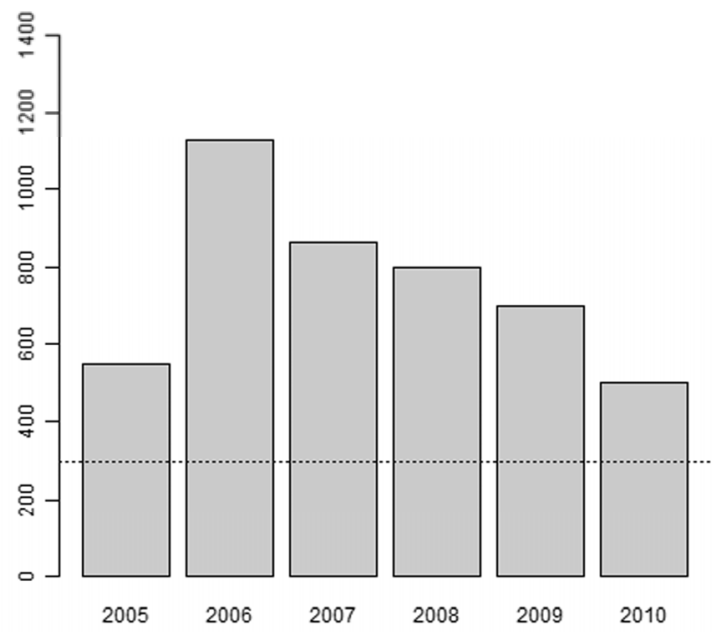

Fig. 8. The risk threshold that would result in a 5\% false positive rate with respect to calendar year.

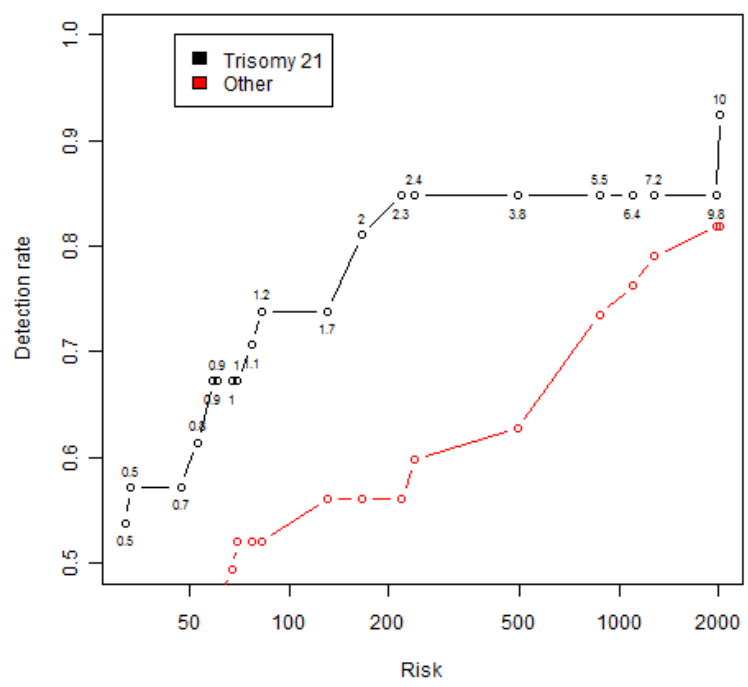

Fig. 9. Detection rate of trisomy 21 (black curve) and other chromosomal abnormalities (red curve) with respect to the risk threshold set (value 200 implies probability threshold set at $1 / 200$ ) - prediction for the Slovene population. The numbers above the points give the false positive rate. 


\section{Discussion}

The retrospective study of the first trimester screening for trisomy 21 in 5-year period from 2005 to 2010 by a combination of maternal age, sonographic measurement of fetal NT thickness and assessment of the fetal nasal bone represented a detection rate of $85 \%$ at a false positive rate of $2.8 \%$.

\subsection{Detection rate}

The findings of many studies suggest that effective first trimester screening for trisomy 21 can be provided only by the combination of maternal age and measurement of fetal NT (Pajkrt E et al, 1998; Economides DL et al, 1998; Bindra R et al, 2002; Liu SS et al, 2004; Rozenberg P et al, 2006; Westin M et al, 2006; Czuba B et al., 2007; Kagan KO et al, 2010). At a risk cut-off of 1 in 100, the detection rate of trisomy 21 is about $75 \%$, at a false positive rate of about $2 \%$.

The detection can be improved to $85 \%$ by the additional assessment of the fetal nasal bone and even more by the Doppler assessment of blood flow across the tricuspid valve or blood flow in the ductus venosus, which increased the detection rate to about $95 \%$ at a false positive rate of $2.5 \%$ (Kagan KO et al, 2010). The disadvantage of the Doppler assessment of tricuspid and ductus venosus flow is that it is time consuming and it requires appropriately trained sonographers (Nicolaides KH 2011).

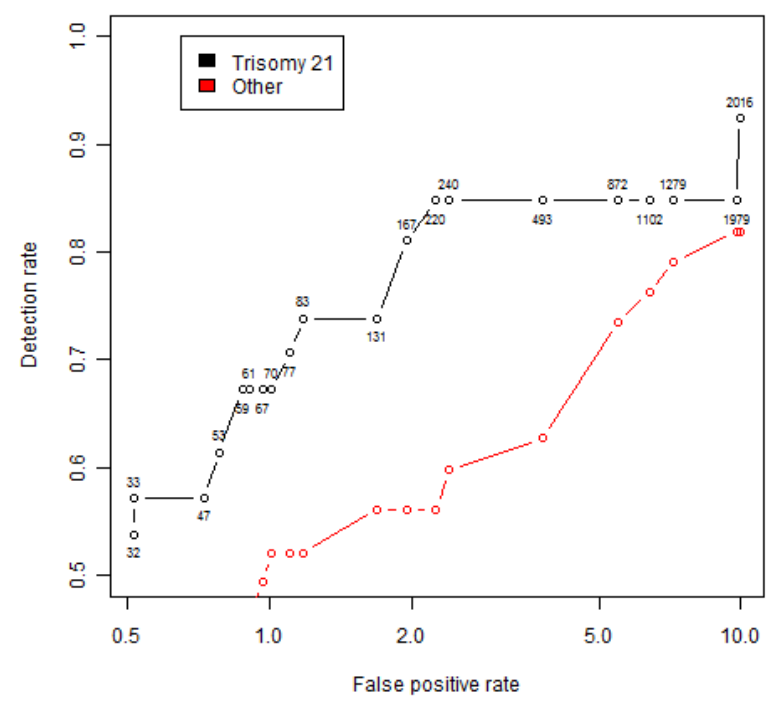

Fig. 10. Detection rate of trisomy 21 (black curve) and other abnormalities (red curve) with respect to the false positive rate - prediction for the Slovene population. The numbers above the points give the risk threshold (value 200 implies probability threshold set at 1/200).

By the measurement of fetal NT thickness and the assessment of the fetal nasal bone we were able to achieve the expected results at a risk cut-off of 1 in 300 . In our sample the relationship between the false positive rate and the detection rate was proved to be in line 
with the prediction from the Nicolaides study (Nicolaides KH 2011) and highly comparable to other reports (Prefumo F et al, 2006; Kagan KO et al, 2010).

Choosing sonographic assessment rather than biochemical testing as a first stage policy has a few advantages. In all sonographically screened pregnancies in addition to chromosomal markers, fetal anatomy is observed and both provide early diagnosis of many major abnormalities, not just in the subgroup with a positive first stage biochemical screening results (Nicolaides KH 2011). Further measurements of maternal serum free $\beta$-hCG and PAPP-A can be limited only to high risk subgroup.

\subsection{Prediction for the Slovene population}

But the trend of ageing the population of pregnant women is noticed and the false positive rate at the risk cut-off 1 in 300 is changing almost linearly with time (Figure 7).

Allowing ourselves 5\% false positive rate in the population, we could lower the risk limit. But, as our detection rate is more than adequate according to FMF guidelines, at the moment we have no reason to actually change it, and we believe that any such change should also be weighted against the risk of pregnancy loss due to invasive testing.

Our calculations show that the FMF recommendations about the risk limit cannot be directly translated to our specific population distribution. We believe the limit that ensures a $5 \%$ false positive rate is constantly changing and could be adjusted within each country. To accurate the changing, the weighting could be performed using a large data set, preferably the data set on which the FMF algorithm was developed, using the respective population maternal age distribution. The only assumption needed for such estimation would be, that conditional on the maternal age, the NT and CRL distributions do not vary among the countries, which we believe is an assumption we can safely make.

\section{Conclusion}

The 11th to 14th weeks scan includes confirmation of the viability of the fetus, accurate dating of the pregnancy, and an early diagnosis of multiple pregnancies and identification of chorionicity.

Effective screening for trisomy 21 can be achieved in the first trimester of pregnancy by a combination of maternal age, sonographic measurement of fetal NT thickness and assessment of fetal nasal bone, with detection rate of $85 \%$ at a false positive rate of less than $3 \%$.

\section{References}

Bindra, R., Heath, V., Liao, A., et al. (2002). One stop assessment of risk for trisomy 21 at 1114 weeks a prospective study of 15030 pregnancies. Ultrasound Obstet Gynecol 20: 219-25.

Cicero, S., Sonek, J.D., McKenna, D.S., et al. (2003). Nasal bone hypoplasia in trisomy 21 at 15-22 weeks' gestation. Ultrasound Obstet Gynecol 21:15-8.

Czuba, B., Borowski, D., Cnota, W., et al. (2007). Ultrasonographic assessment of fetal nuchal translucency (NT) at 11th and 14th week of gestation - Polish multicentre study. Neuro Endocrinol Lett 28: 175-81. 
Economides, D.L., Whitlow, B.J., Kadir, R., et al. (1998). First trimester sonographic detection of chromosomal abnormalities in an unselected population. Br J Obstet Gynaecol 105: 58-62.

Fetal Medicine Foundation. Online-education. Available from: http:// www.fetalmedicine.com/fmf/

Kagan, K.O., Wright, D., Spencer, K., Molina, F.S. \& Nicolaides K.H. (2008). First-trimester screening for trisomy 21 by free beta-human chorionic gonadotropin and pregnancy-associated plasma protein-A: impact of maternal and pregnancy characteristics. Ultrasound Obstet Gynecol 31: 493-502.

Kagan, K.O., Staboulidou, I., Cruz, J., et al. (2010).Two-stage first-trimester screening for trisomy 21 by ultrasound assessment and biochemical testing. Ultrasound Obstet Gynecol 36: 542-7.

Liu, S.S., Lee, F.K., Lee, J.L., et al. (2004). Pregnancy outcomes in unselected singleton pregnant women with an increased risk of first-trimester Down's syndrome. Acta Obstet Gynecol Scand 83: 1130-4.

Nicolaides, K.H., Azar, G., Byrne, D., et al. (1992). Fetal nuchal translucency: ultrasound screening for chromosomal defects in the first trimester of pregnancy. BMJ 304(6831): 867-9.

Nicolaides, K.H., Brizot, M.L. \& Snijders, R.J.M. (1994). Fetal nuchal translucency: ultrasound screening for fetal trisomy in the first trimester of pregnancy. BJOG 101:782-6.

Nicolaides K.H. (2004). Fetal Medicine Foundation. The 11-13+6 weeks scan, pp. 1-112, London, UK

Nicolaides, K.H. (2011). Screening for fetal aneuploidies at 11 to 13 weeks. Prenat Diagn 31: 7-15.

Pajkrt, E, van Lith, J.M.M., Mol, B.W.J., et al. (1998). Screening for Down's syndrome by fetal nuchal translucency measurement in a general obstetric population. Ultrasound Obstet Gynecol 12: 163-9.

Prefumo, F., Sairam, S., Bhide, A., et al. (2006). First-trimester nuchal translucency, nasal bones, and trisomy 21 in selected and unselected populations. Am J Obstet Gynecol 194: 828-33.

Rozenberg, P., Bussières, L., Chevret, S., et al. (2006). Screening for Down syndrome using first-trimester combined screening followed by second-trimester ultrasound examination in an unselected population. Am J Obstet Gynecol 195: 1379-87.

Statistical Office of the Republic of Slovenia. SI-STAT data portal. Available from: http://www.stat.si/pxweb/Database/Dem_soc/05_prebivalstvo/10_rojeni_umrli /01_05544_rojeni/01_05544_rojeni.asp

Snijders, R.J.M., Noble, P., Sebire, N., et al. (1999). UK multicentre project on assessment of risk for trisomy 21 by maternal age and fetal nuchal translucency thickness at 10 14 weeks of gestation. Lancet 18: 519-21.

Westin, M., Saltvedt, S., Bergman, G., et al. (2006). Is measurement of nuchal translucency thickness a useful screening tool for heart defects? A study of 16,383 fetuses. Ultrasound Obstet Gynecol 27: 632-9.

Wright, D., Kagan, K.O., Molina, F.S., Gazzoni, A. \& Nicolaides K.H. (2008). A mixture model of nuchal translucency thickness in screening for chromosomal defects. Ultrasound Obstet Gynecol 31:376-383. 


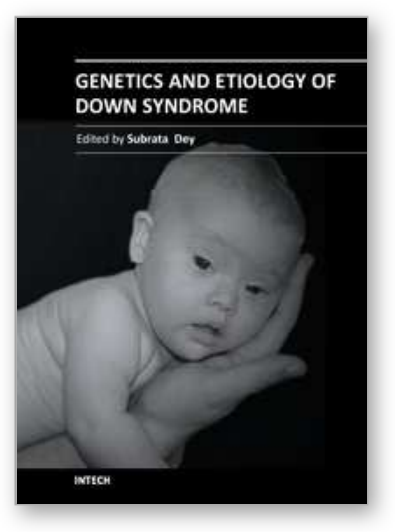

\author{
Genetics and Etiology of Down Syndrome \\ Edited by Prof. Subrata Dey
}

ISBN 978-953-307-631-7

Hard cover, 328 pages

Publisher InTech

Published online 29, August, 2011

Published in print edition August, 2011

This book provides a concise yet comprehensive source of current information on Down syndrome. Research workers, scientists, medical graduates and paediatricians will find it an excellent source for reference and review. This book has been divided into four sections, beginning with the Genetics and Etiology and ending with Prenatal Diagnosis and Screening. Inside, you will find state-of-the-art information on: 1. Genetics and Etiology 2. Down syndrome Model 3. Neurologic, Urologic, Dental \& Allergic disorders 4. Prenatal Diagnosis and Screening Whilst aimed primarily at research workers on Down syndrome, we hope that the appeal of this book will extend beyond the narrow confines of academic interest and be of interest to a wider audience, especially parents and relatives of Down syndrome patients.

\title{
How to reference
}

In order to correctly reference this scholarly work, feel free to copy and paste the following:

Ksenija Gersak, Maja Pohar-Perme and Darija M. Strah (2011). First Trimester Screening for Trisomy 21 by Maternal Age, Nuchal Translucency and Fetal Nasal Bone in Unselected Pregnancies, Genetics and Etiology of Down Syndrome, Prof. Subrata Dey (Ed.), ISBN: 978-953-307-631-7, InTech, Available from: http://www.intechopen.com/books/genetics-and-etiology-of-down-syndrome/first-trimester-screening-fortrisomy-21-by-maternal-age-nuchal-translucency-and-fetal-nasal-bone-in

\section{INTECH}

open science | open minds

\author{
InTech Europe \\ University Campus STeP Ri \\ Slavka Krautzeka 83/A \\ 51000 Rijeka, Croatia \\ Phone: +385 (51) 770447 \\ Fax: +385 (51) 686166 \\ www.intechopen.com
}

\author{
InTech China \\ Unit 405, Office Block, Hotel Equatorial Shanghai \\ No.65, Yan An Road (West), Shanghai, 200040, China \\ 中国上海市延安西路65号上海国际贵都大饭店办公楼 405 单元 \\ Phone: +86-21-62489820 \\ Fax: $+86-21-62489821$
}


(C) 2011 The Author(s). Licensee IntechOpen. This chapter is distributed under the terms of the Creative Commons Attribution-NonCommercialShareAlike-3.0 License, which permits use, distribution and reproduction for non-commercial purposes, provided the original is properly cited and derivative works building on this content are distributed under the same license. 